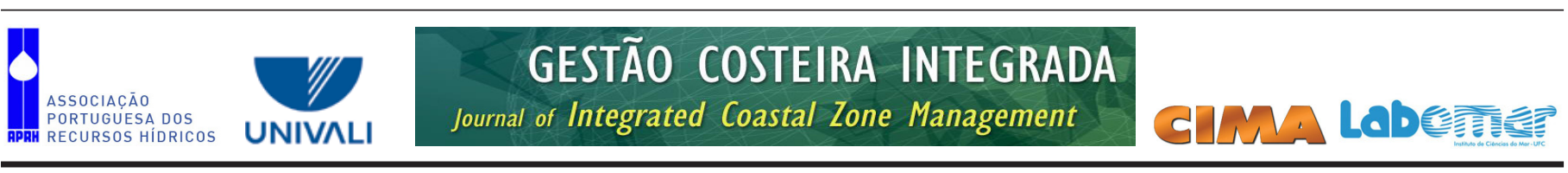

http://www.aprh.pt/rgci/pdf/rgci-424_Seixas.pdf | DOI:10.5894/rgci424

\title{
Percepção de pescadores e maricultores sobre mudanças ambientais globais, no litoral Norte Paulista, São Paulo, Brasil *
}

\section{Perception of fishermen and shellfish producers on global environmental changes in the Northern Coast of São Paulo State, Brazil}

\author{
Sônia Regina da Cal Seixas ${ }^{\circledR, 1,2}$, João Luiz de Moraes Hoeffel ${ }^{3}$, Michelle Renk ${ }^{2}$, \\ Benedita Nazaré da Silva ${ }^{3}$, Fábio Bueno de Lima ${ }^{4}$
}

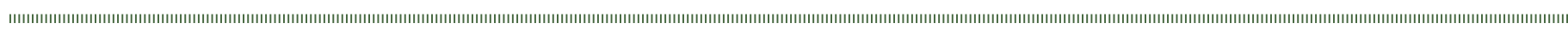

\section{RESUMO}

As mudanças ambientais globais envolvem alteraçóes no clima e nos sistemas ecológicos, incidem nos ciclos naturais, determinando prejuízos à infraestrutura, às atividades econômicas, sociais e à saúde humana, afetando, principalmente, as populaçôes mais vulneráveis. Hoje, estima-se que as zonas costeiras são as regiôes que mais sofrerão esses impactos, com efeitos diretos na economia e no cotidiano de suas comunidades. Fenômenos como o aumento de temperatura, do nível dos oceanos e da salinidade, eventos extremos, perdas das áreas de várzea e manguezais costeiros, aliados à ocupaçáo desordenada do solo, pela construção de grandes empreendimentos tecnológicos e por turismo de massa, poderão afetar diretamente essas regióes. Estudar o Litoral Norte Paulista se justifica porque este tem sofrido impactos decorrentes das mudanças ambientais globais e porque suas comunidades expressam forte vulnerabilidade socioambiental. $\mathrm{O}$ objetivo deste artigo é verificar a percepçáo dos pescadores artesanais da praia da Cocanha/Caraguatatuba, Litoral norte paulista, Brasil, por meio de entrevistas semiestruturadas e da observaçáo direta de seu cotidiano, para averiguar, através dessa metodologia, sua percepção sobre a variação da temperatura do mar, sobre o volume de chuvas e sobre a imprevisibilidade das condiçóes climáticas em geral. A análise dos dados, provenientes das entrevistas com os pescadores artesanais, sobre sua percepção sobre os impactos dessas mudanças, contribuirá para o melhor entendimento da vulnerabilidade e dos riscos aos quais estáo submetidos, e a sua relação intrínseca com as mudanças ambientais globais sofridas.

Palavras-chaves: vulnerabilidade; empreendimentos tecnológicos; turismo; Caraguatatuba; Praia da Cocanha.

\section{ABSTRACT}

Global environmental changes involve changes in climate and ecological systems, on natural cycles, causing damages to infrastructure, to economic and social activities and to human health, affecting populations in various parts of the planet, mainly the more poor and vulnerable populations, and those that are subjected to precarious general services and environmental urban infrastructure. Today, it is estimated that coastal

@ - Corresponding author-e-mail:srcal@unicamp.br

1 - Núcleo de Estudos e Pesquisas Ambientais (NEPAM)/Universidade Estadual de Campinas, São Paulo, Brasil.

2 - Universidade Estadual de Campinas, Doutorado Ambiente e Sociedade/NEPAM, São Paulo, Brasil.

3 - Núcleo de Estudos em Sustentabilidade e Cultura, Faculdades Atibaia (NESC/FAAT), Atibaia, São Paulo, Brasil.

4 - Moinho d'Água Treinamentos, São Paulo, Brasil. 
areas are the regions that will most suffer these impacts, with direct effects on the economy and daily life of their communities. Simultaneously to the observation of increasing problems, there is great progress in research on global environmental change, where the human dimensions have been prioritized. This task, however, has been a major challenge today. The construction and history of the concept of global and urban environmental change have occurred mostly in recent decades, from a perspective of human dimensions, including systemic changes that operate globally through the major systems of the geosphere-biosphere, while that cause cumulative changes in both the global and local perspective, and should be considered across different spatial scales. Phenomena such as increased temperature, sea level and salinity, extreme events, loss of floodplains and coastal mangroves, connected with disorderly soil use, the construction of large technological developments and mass tourism, may directly affect these regions. To understand this approach and the "locus" where our thinking is inserted is important to consider that the contemporary world is undergoing an interaction of two major global processes: climate change and economic globalization. Thus, it is believed that the globalization of economic processes that promote large impacts, and climate change associated with them are the great challenge of this century, due to the changes that may originate and can cause damage to the economic and social systems, human health and quality of life. Thus, studying the North Coast Paulista is justified because this area is suffering impacts of global environmental change and because their communities express strong socioenvironmental vulnerability. The choice of Cocanha beach, located in the northern area of Caraguatatuba, Säo Paulo, Brasil, is justified by being a good example of changes that have occurred in the region, and because this municipality is considered the gateway to the northern coast of Sáo Paulo State. Cocanha, as well as other beaches in the region, has suffered strong influence of tourism and a growing process of land use, which occurred from the 1950s, with the opening of Highway Tamoios (SP -099), which connects the Northern Coast of Säo Paulo State to the industrialized Vale do Paraiba, combined with improvements in regional infrastructure that arise from the project to expand São Sebastiäo Harbor. In addition the beach of Cocanha has great relevance to the region in terms of tourism and economy, since it is characterized as the largest producer of mussels of the State of São Paulo. The purpose of this article is to verify the perception of fishermen that work at this beach, through semi-structured interviews and direct observation of their daily lives, to ascertain, through this methodology, their perception on the sea temperature variation, on the rainfall and on the unpredictability of the weather in general. This methodological choice is justified because there is a tradition of research where the perception of fishermen and traditional knowledge of fishing communities, even if realized using different theoretical approaches and methodologies, represent an inexhaustible source of knowledge and reference information on various aspects, and can help to allow a broader understanding of the reality of the use of natural resources, as well as important evidence about the study area. And in many situations this perception and knowledge may influence in planning, adaptation and mitigation for numerous situations of risk and social vulnerability, that many of these populations are subjected. In interviews with fishermen, it became clear the perception they have on the temperature variation of seawater over time, increased rainfall and unpredictable climatic conditions, which are perceived as the major interference in their activities, both fishing and shellfish culture, showing to them a decrease in their fish production. The analysis of data from interviews with fishermen, on their perceptions of the impact of these changes may contribute to a better understanding of the vulnerability and the risks to which they are subjected, and its intrinsic relationship with the global environmental changes suffered, as well as for the indication and formulation of public policies that can mitigate the problems highlighted.

Keywords: vulnerability; technological development; tourism; Caraguatatuba; Cocanha Beach.

\section{INTRODUÇÃO}

Nos últimos anos, tem-se observado um grande avanço nas pesquisas sobre mudanças ambientais globais, em que as dimensóes humanas têm sido priorizadas. Autores como Muller \& Jacobson (1992) já apontavam, em 1992, que, como as pesquisas vinham avançando, mudanças nas escalas de tempo e espaço também passariam por alteraçōes significativas, fazendo com que as Ciências Sociais, por exemplo, passassem a organizar novas estruturas institucionais para conduzir e coordenar esse tipo de pesquisa e, consequentemente, oferecer novos arcabouços teóricos e metodológicos ${ }^{1}$. Essa tarefa, no entanto, tem sido um grande desafio até hoje. Contudo, a construção e a trajetória do conceito de mudanças ambientais globais e urbanas têm ocorrido de forma singular. Nos anos 1990, Turner II et al. (1990:14) descreveram que mudança ambiental global, a partir de uma perspectiva das dimensóes humanas, inclui

1 - Para uma ampla e importante abordagem sobre o desenvolvimento desse processo, reportamos o leitor para Miller, R B and Jacobson, H K. Research on the human components of global change. Next steps. Global Environmental Change, September 1992: 170- 182. alteraçóes sistêmicas que operam globalmente através dos principais sistemas da geosfera-biosfera, ao mesmo tempo em que provocam mudanças cumulativas tanto no plano global quanto local, e deve ser considerada através de diferentes escalas espaciais.

Para a compreensão dessa abordagem e do "locus" onde nossa reflexão está inserida, é importante considerar O’Brien $\&$ Leichenko (2002), que, de forma determinante, afirmam que o mundo contemporâneo está submetido a uma sinergia de dois grandes processos globais: mudanças climáticas e globalização econômica. Para os autores, ambos os processos envolvem mudanças de longo prazo que terão impactos diferenciais em todo o mundo. Os autores afirmam, no entanto, que essas duas questóes, que chamam de "dupla exposição" (p. 227) - ou, no nosso entender, vulnerabilidade e riscos -, não são, em geral, tratadas em conjunto. Para eles, "dupla exposição" refere-se ao fato de que certas regióes, setores, ecossistemas e determinados grupos sociais serão confrontados tanto pelos impactos das mudanças climáticas quanto pelas consequências da globalização.

$\mathrm{Na}$ nossa compreensão, a globalização dos processos econômicos, que promovem grandes impactos, e as mudanças climáticas a eles associadas são o grande desafio do século XXI, pois envolvem alteraçôes no clima, nos sistemas 
ecológicos e incidem sobre a infraestrutura existente e os ciclos naturais, podendo provocar prejuízos às atividades econômicas, sociais, à saúde humana e à qualidade de vida, afetando as populaçóes de várias partes do planeta, mas de forma mais intensa as populaçóes mais pobres e que estáo submetidas a serviços e infraestruturas ambientais urbanas mais precárias (Turner II et al., 1990; Giddens, 2010; Kotir, 2010; Min et al., 2011; Patz et al., 2007).

A literatura científica tem evidenciado que eventos extremos (secas, enchentes, ondas de calor e de frio, furacōes e tempestades) têm afetado de forma diversa o planeta, causando perdas econômicas e humanas e comprometendo a biodiversidade, provocando aumento médio no nível do mar e impactos na saúde, agricultura e geração de energia hidrelétrica (Abraham et al., 2013; Oven et al., 2012; Fuchs et al., 2011; Marengo \& Valverde, 2007; Mendonça, 2005).

No entanto, há também forte evidência de que as regiōes costeiras serão as mais impactadas por variaçóes climáticas. Trabalhos como os de Adger \& Kelly (2005), Marengo (2006), Nicolodi \& Petermann (2010), Delicado et al. (2012) e Sherbinin et al. (2007) já vêm alertando para essa situação, inclusive na dimensão de "dupla exposição" (apresentada por O’Brien \& Leichenko, 2002: 227), na medida em que alguns desses impactos afetarão diretamente a economia e o cotidiano das comunidades dos municípios litorâneos, principalmente aquelas onde a vulnerabilidade ambiental e social já se fazem presentes.

Como destacaram Dias et al. (2009), mais de 50\% da população mundial vive no entorno de $60 \mathrm{~km}$ do litoral, competindo em uma estreita fixa de costa por recursos naturais e terra, e esse tipo de situação demanda novos interesses, como a convivência de atividades tradicionais com novas demandas econômicas (existência e ampliação de atividades portuárias, turismo de massa, interesses econômicos, como o imobiliário, por exemplo), novos conflitos e pressóes passam a existir e, muitas vezes, criando grandes entraves para a conservação ambiental. Essa realidade fica mais impactada quando se percebe que, no caso brasileiro, até 2010, não havia um estudo de vulnerabilidade da costa brasileira para os impactos decorrentes de mudanças climáticas em escala nacional, e, assim mesmo, os dados disponíveis não eram suficientes para a elaboraçâo de cenários de impactos nas zonas costeiras advindos de mudanças climáticas (Nicolodi \& Petermann, 2010:175).

Ao mesmo tempo, Nicolodi \& Petermann (2010) ressaltam que já existe um cenário positivo no fato de algumas pesquisas científicas terem se voltado para regiōes onde a vulnerabilidade social e os riscos de impactos climáticos se fazem mais presentes. Em tais regiôes, a baixa altitude, o forte contingente populacional, amplas carências sociais e complexas redes tecnológicas, que favorecem a vulnerabilidade e os riscos e aumentam o grau de impacto, devem ser prioridade tanto de pesquisadores quanto do Poder Público.

As consequências com maior grau de previsibilidade para as regióes litorâneas são as perdas das áreas de várzea e manguezais costeiros e o aumento dos danos causados por inundaçôes no litoral, derivados da combinação entre a elevaçáo do nível do mar e o desenvolvimento humano com ocupação desordenada do solo (Solomon et al., 2007). E, ainda segundo outros autores, fenômenos como o aumento de temperatura e do nível dos oceanos, salinidade, acidificação dos mares e o aumento de eventos extremos (Bindoff \& Willebrand, 2007; Neves \& Muehe, 2008; Nicolodi \& Petermann, 2010; Abraham et al., 2013). Outras pesquisas científicas ilustram essa problemática, tais como as realizadas por Adger \& Kelly (2005), Confalonieire (2005), Marengo (2006), Sherbinin et al. (2007), Delicado et al. (2012), Egler \& Gusmão, in press e Bitencourt \& Rocha, in press.

As pesquisas no Litoral Norte que temos conduzido são um exemplo desse alerta que temos procurado oferecer (Seixas et al., 2010; 2011; 2012; Botterill et al., 2013), pois, considerando as características do litoral norte paulista, como elevada concentração demográfica, urbana e econômica, e o incremento de megaprojetos tecnológicos, acredita-se que a ocorrência e a intensificação dos impactos das mudanças climáticas afetará direta e indiretamente as atividades econômicas regionais, principalmente aquelas ligadas à pesca e à maricultura.

Outra questão a considerar nesta área de estudo são os impactos socioambientais do turismo. $\mathrm{O}$ turismo, se não for bem planejado, pode provocar, ou mesmo dinamizar, alterações ambientais e o agravamento da exclusão social (Cooper et al., 2002; Ruschmann, 2006; Coriolano, 2008). O turismo, na visão de Honey (2010), depende da apropriaçáo e exploraçáo da natureza e das sociedades locais, podendo gerar a degradação ambiental e sociocultural de forma expressiva através da utilizaçáo não-sustentável de suas fontes de matérias-primas e posterior transferência para outros locais de exploração.

Observam-se, dessa forma, diversos aspectos negativos, como o não envolvimento das comunidades locais nas decisōes e na renda gerada, a desvalorização de características culturais, a degradação dos aspectos naturais, a criação de imagens incompatíveis com a realidade social e, sobretudo, a padronização dos lugares. Todos esses impactos têm como questão central a ocupação, construção e redefinição do espaço turístico.

Nesse contexto, ressalta-se a necessidade de ser o planejamento turístico uma contribuição para o planejamento do lugar e da vida daqueles que lá permanecem, adequandose à realidade preexistente no cotidiano do lugar. Por essa razão, na medida em que o planejamento da atividade turística estiver preocupado apenas em converter lugares em atrativos, será difícil eliminar o caráter artificial que se observa nos destinos turísticos.

Assim, muitos dos problemas apontados como impactos negativos do turismo estáo associados ao processo de transformaçáo da "natureza do lugar" em favor da construção do "lugar do turismo". Dessa forma, ressalta-se a importância de planejamentos turísticos participativos que envolvam o Poder Público, a iniciativa privada e, em especial, as comunidades locais e que promovam a melhoria da qualidade de vida, a valorização dos aspectos socioambientais e o fortalecimento da identidade local (Krippendorf, 2000; Machado et al., 2009).

Segundo Mendonça (2006), na formação dos centros turísticos, a população nativa é, em geral, afastada de seu local de moradia e de atividade de origem. Isso se dá das mais diversas formas, seja fisicamente, vendendo sua terra e 
deslocando-se para outro lugar, seja participando de forma marginal da economia, seja desprezando seus próprios valores culturais e adotando os novos trazidos pelos turistas (Mendonça, 2006).

Souza et al., (2008) apresentam análises semelhantes em seu trabalho sobre o desenvolvimento turístico na zona Costeira do Ceará, Brasil, e, mais especificamente, no município de Paracuru, e ressaltam que são poucos os casos em que a atividade turística ocorre de forma compatível com a preservação dos recursos naturais e socioculturais. Segundo os autores, o mau uso do solo e o processo desordenado de ocupação na área por eles analisada não se deram de forma harmônica, levando a eventos adversos que vão desde a descaracterização da cultura popular local até processos erosivos.

A criação de Unidades de Conservação tem auxiliado na proteção e preservaçáo dos recursos naturais da zona costeira e indicam medidas para o uso sustentável e para o desenvolvimento da regiấo que auxiliem na minimização dos impactos socioambientais observados. Coriolano et al., (2008) e Coriolano (2008) também analisam, em seus trabalhos, a relaçáo do turismo na região costeira do Ceará com a exclusão social e seus impactos sobre as comunidades tradicionais, o que torna insustentável, em alguns casos, esta atividade.

O trabalho de Coriolano et al., (2008) indica que as comunidades pesqueiras litorâneas não têm sido incluídas no desenvolvimento do turismo do Estado do Ceará de forma justa, o que tem sido um grave problema no litoral. Devido ao avanço da especulação imobiliária, as populaçôes tradicionais moradoras das áreas litorâneas têm sido expulsas para áreas periféricas da Grande Fortaleza, fato que se acentua, também, em função de deslocamentos compulsórios determinados por novos usos e apropriaçóes.

Nessa perspectiva se insere a área de estudo deste trabalho, o litoral norte paulista e, em especial, o município de Caraguatatuba, que tem passado por um acelerado processo de transformaçôes socioambientais que resultam em uma elevada expansão demográfica e urbana, um expressivo processo turístico desordenado e o incremento significativo de megaprojetos tecnológicos, além da intensificação dos impactos das mudanças ambientais globais. No conjunto, a interaçáo desses processos se reflete tanto num processo de degradaçáo pessoal e coletivo quanto ambiental.

\section{METODOLOGIA}

$\mathrm{Na}$ medida em que as pesquisas realizadas são assumidas e marcadamente interdisciplinares, com interface com a sociologia ambiental, a psicologia social, o planejamento ambiental e também com as ciências naturais, dentre as mais expressivas ${ }^{2}$, o interesse dos autores neste artigo é abrir

2 - O conjunto de pesquisas que possibilita este artigo são, a saber: Urban growth, vulnerability and adaptation: social and ecological dimensions of climate change on the coast of São Paulo (FAPESP no 2008/58159-7), Mudanças ambientais globais, vulnerabilidade, risco e subjetividade: um estudo sobre o Litoral Norte Paulista (FAPESP no. 2010/20811-5) e Energia e Qualidade de Vida no Litoral Norte Paulista (FAPESP no. 2011/20803-5). um diálogo com outros interlocutores que se preocupam marcadamente com a gestâo integrada da costa. Assim, em alguns momentos diferenciados, referenciais das mesmas pesquisas já foram publicados e ou apresentados em Congressos Internacionais (e.g., Seixas et al,. 2011; 2012) e propiciaram aos autores principais um diálogo fundamental para o avanço das pesquisas.

Os projetos incidem nos quatro municípios do litoral norte do Estado de São Paulo, mas esse artigo é estimulado a partir de uma análise aprofundada sobre a percepçáo dos pescadores e maricultores da praia da Cocanha, no município de Caraguatatuba, no que diz respeito a mudanças ambientais globais e seus possíveis impactos na atividade pesqueira da região. Para tanto, foram realizadas observação direta da realidade dos pescadores e suas famílias, conversas informais durante o período em que se encontravam na atividade na praia e, a partir desses primeiros contatos, foram realizadas 13 entrevistas semiestruturadas, com uma amostra escolhida aleatoriamente entre os pescadores e maricultores, vinculados à Associação dos Maricultores e Pescadores da Coconha (MAPEC) e que se dispuseram a conversar com os pesquisadores, no período de novembro de 2009 a fevereiro de 2011.

As entrevistas foram compostas por perguntas abertas procurando obter uma prévia dos fatores que possam estar envolvidos na interface entre as mudanças ambientais globais e a atividade de pesca, de acordo com a percepção desses trabalhadores. A estrutura das entrevistas foi orientada por quatro temas centrais: 1. Dados gerais de Identificação do pescador (local de nascimento; local de moradia; idade e tempo de prática na atividade); 2 . Como era a atividade no passado; 3. Como é a atividade no presente e 4 . O que eles percebem que mudou e que provocou a mudança. Além das entrevistas, foi visitada a Ilha da Cocanha e a fazenda de cultivo de mexilhóes. As entrevistas foram integralmente transcritas e sistematizadas a partir do software NVIVO8.

Acreditamos e compartilhamos essa perspectiva com Delicado et al. (2012), quando ressaltam que "os pescadores que vivem na e da costa têm uma visão privilegiada das mudanças costeiras e, em resultado da sua atividade, detêm um conhecimento que, apesar de não ser técnico, se baseia na experiência e é especifico do local' (Delicado et al., 2012:437). E, desta forma, o que se pode afirmar como resultado é que os pescadores revelam um conhecimento importante e específico sobre mudanças ambientais significativas, que estão ocorrendo na praia da Coconha e que têm modificado a paisagem da praia e interferido nos recursos naturais e em suas atividades de trabalho.

\subsection{Consideraçóes acerca da área de estudo: Praia da Cocanha, Caraguatatuba, Litoral Norte Paulista.}

A praia da Cocanha está localizada na porção norte de Caraguatatuba, limitada no eixo norte-sul pelas praias Mococa e Massaguaçu (Figura 1). O município é considerado o portal de entrada para o litoral norte paulista (Figura 2) e, assim, a Cocanha, bem como outras praias da região, tem sofrido forte influência do turismo e de um processo crescente de ocupação do solo, que se deu a partir da década de 1950, com a abertura da Rodovia dos Tamoios (SP-099), que liga 


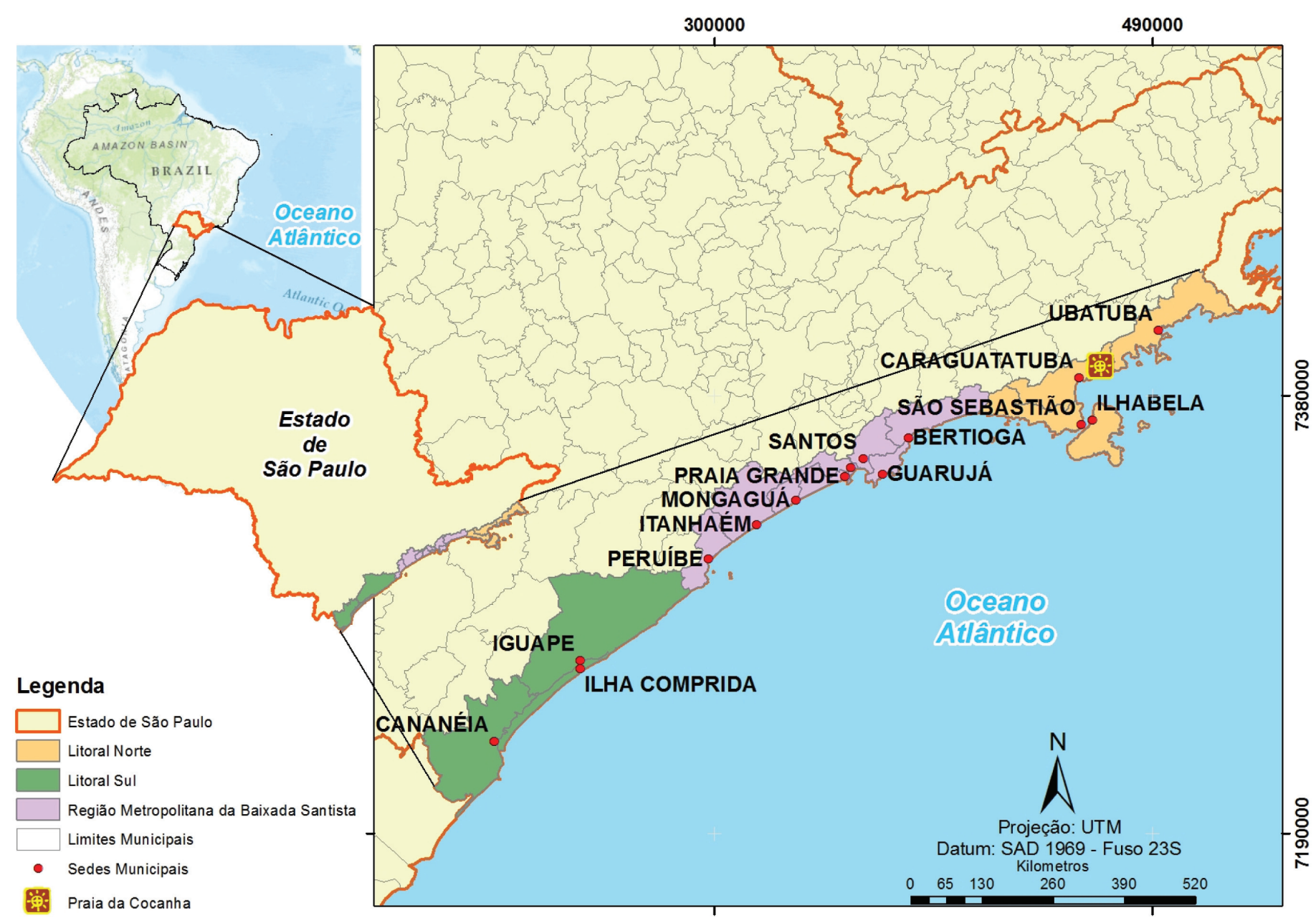

Figura 1. Litoral do Estado de São Paulo.

Figure 1. Coast of São Paulo State.

o Litoral Norte ao Vale do Paraíba, aliada a melhorias na infraestrutura regional provenientes da obra de ampliação do Porto de São Sebastiâo (Souza, 2009).

A praia da Cocanha possui grande relevância para a região em termos turísticos e econômicos, uma vez que é caracterizada como a maior produtora de mexilhōes do Estado de Sáo Paulo, com cerca de 30 toneladas/ano (Marques et al., 2008). De acordo com Marques et al. (2008: 87), a mitilicultura na Praia da Cocanha teve início em 1989, através de um processo de capacitação dos pescadores, promovido pela Secretaria do Meio Ambiente do Estado de São Paulo, com assessoria do Instituto de Pesca (SP) e da Associação dos Maricultores do Estado de São Paulo - AMESP (Marques et al., 2008; Prado, 2001). Posteriormente, em 2000, a MAPEC foi fundada e, em 2008, contava com cerca de 40 associados, entre pescadores e maricultores, membros da comunidade local. Apesar de sua importância no cenário nacional como produtora, vale ressaltar que a produção varia muito de ano para ano, pois são poucos os produtores que se dedicam de forma exclusiva e continuada à mitilicultura (Marques, et al., 2008).

$\mathrm{Na}$ observação direta que foi realizada pelos autores no período da pesquisa, percebe-se que, em 2009, a Associação contava com um total de 40 associados e 35 em 2011. No primeiro momento, $37,5 \%$ dos entrevistados dedicam-se à mitilicultura. A porcentagem de maricultores subiu cerca de 5\% em 2011, devido à diminuição de pescadores associados. Nota-se que o número de associados sofreu, ao longo do tempo, inúmeras variaçóes para mais ou para menos, no entanto essa média tem sido predominante, e o universo dos entrevistados representa 32\% desse total.

Sobre a maricultura, vale destacar que sua importância econômica no Brasil é recente e, atualmente, bastante difundida em todo o litoral brasileiro, demonstrando-se economicamente viável e uma forma de gerar empregos e renda, principalmente para moradores locais, que já têm repertório de desenvolvimento de trabalho no mar (Silvestri et al., 2011). Mas, para se ter uma ideia da importância econômica do setor, Boscardin (2008) aponta que a produçáo mundial da aquicultura em 2004 foi de 59 milhóes de toneladas, com uma geração de renda de aproximadamente US\$ 70,3 bilhóes. A China foi a líder na produção, com $70 \%$ (41,3 milhóes de toneladas) do total e $51 \%$ (US\$ 36 bilhôes) da geração de receitas. A produçáo aquícola e pesqueira brasileira alcançaram, no ano de 2004, um volume de 1.015.916 toneladas, participando com 26,5\% 


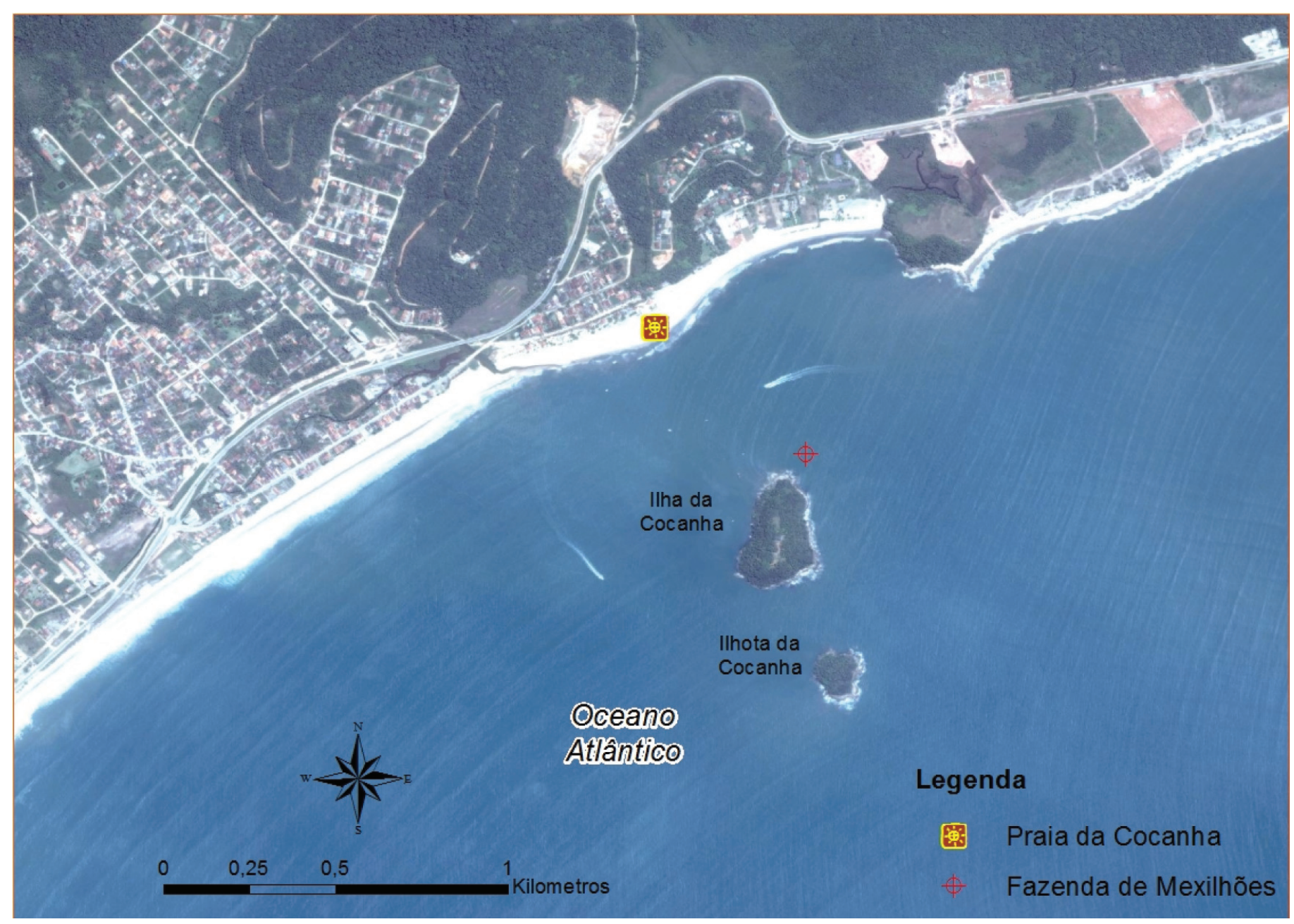

Figura 2. Praia da Cocanha.

Figure 2. Cocanha Beach.

(269.697,50 toneladas) na produção total do Brasil, gerando US\$ 965.627,60 (Boscardin, 2008: 27).

Em 2004, a produção de moluscos representou 4,8\% da produção aquífera brasileira. Desse total, $79,5 \%$ são representados pelo cultivo da espécie Perna perna, nativo, seguido pelo de ostras, com 20,5\%, gerando receitas de US\$ 9,3 milhôes naquele ano (Boscardin, 2008). O Estado de Santa Catarina, no mesmo ano, foi responsável por 94,5\% da produção do ano, enquanto o restante $(5,5 \%)$ é distribuído nos estados do Espírito Santo, São Paulo e Rio de Janeiro (Boscardin, 2008).

De acordo com os maricultores da Cocanha, o cultivo de mexilhóes é realizado no parque aquícola da Ilha da Cocanha (ver figura 1), em uma área aproximada de $62.000 \mathrm{~m}^{2}$, com $5 \mathrm{~m}$ a $8 \mathrm{~m}$ de profundidade, abrigando nove cultivos em operaçáo em 2009, sendo que a capacidade total é de 11 cultivos (Silvestri, 2009; Sinau, 2009). O cultivo é dividido em ciclos com duração de 8 a 9 meses, sendo esta produção intensificada nos meses de novembro a janeiro devido à demanda do período de temporada de veraneio (Silvestri, 2009).
No Estado de São Paulo, o cultivo de mexilhóes é realizado de forma semi-artesanal, por famílias tradicionais e comunidades de pescadores, empregando mão-de-obra familiar (Manzoni, 2004; Josupeit, 2005; Marques et al., 2008; Ostrensky; Boeger, 2008; Ostrensky et al., 2008). Para Fagundes et al. (2004), a mitilicultura surge como alternativa de renda para comunidades que vivem da pesca e que possam permanecer em seus locais de origem, diante do declínio dos estoques pesqueiros, consequentes da pesca predatória e da poluição.

\section{RESULTADOS e DISCUSSÁO}

\subsection{Breve perfil demográfico dos entrevistados}

Apesar de nossa estratégia metodológica indicar uma escolha aleatória dos entrevistados pertencentes à MAPEC, é sabido que toda escolha tem um suporte que a orienta, e, no caso específico desta pesquisa, era fundamental que morassem na região e que tivessem um tempo significativo de prática na atividade pesqueira. Assim, no trabalho de campo, ficou evidenciado que a maior parte dos pescadores e maricultores nasceram e residem na regiáo $(80 \%)$, apresentam tempo 
médio de atividade de 19 anos e faixa etária de 34 a 54 anos. Outro aspecto importante observado é que as famílias participam intensamente do trabalho, principalmente esposas e irmãos, que contribuem, especialmente, na limpeza dos mexilhōes. Sobre este aspecto, Pestana et al. (2008) salientam que a aquicultura, no geral, apresenta grande potencial de absorção de mão-de-obra e geração de renda, mas não de gerar empregos. Sobre esse aspecto, os autores ressaltam que a coleta de informaçóes sobre a geraçáo de empregos na aquicultura brasileira é pouco eficiente, pois o único censo foi realizado pelo IBGE (Instituto Brasileiro de Geografia e Estatística) em 2000 e baseou-se, exclusivamente, nos produtores que declararam ter na aquicultura sua atividade econômica principal, o que não necessariamente representa o conjunto dos trabalhadores da atividade (Pestana et al., 2008:131). Essa questão foi observada na Cocanha através do elevado número de pessoas que consideram o cultivo de mexilhôes como renda complementar, fato esse já explorado sob outros aspectos em Seixas et al. (2011).

\subsection{A relaçáo dos pescadores e maricultores com sua atividade produtiva}

Os pescadores e maricultores da regiáo de estudo, organizados em sua Associação-MAPEC, atuam estruturados em um rancho localizado na praia, que conta com 22 boxes e um galpão central, para auxiliar na guarda do material e de embarcações utilizadas na atividade da pesca e maricultura e na venda dos produtos. No começo das atividades da produção de mexilhóes, na praia da Cocanha, a comercialização do produto era realizada, em sua maioria, através de compradores diretos, turistas e para consumo na praia e em restaurantes, sendo nesse início bastante incipiente, segundo os relatos; contudo, atualmente, a procura ultrapassa a produção. Os entrevistados atribuem esse crescimento do mercado local ao festival do mexilhão, realizado com incentivo da Prefeitura Municipal, que, em 2010, realizou sua nona edição e contou com oito mil participantes e quatro mil quilos de mexilhões consumidos (Almeida, 2010).

Apesar de reconhecerem que o mercado consumidor do mexilhão na região aumentou, as informações sobre o perfil de fonte de renda dos entrevistados demonstra que apenas um pescador (entrevistado 6) possui sua renda exclusiva na pesca, enquanto três maricultores possuem a mitilicultura como única atividade. Assim, 69\% dos entrevistados possuem renda complementar, seja na prática da pesca aliada à maricultura ou em trabalhos em outros segmentos, como prestação de serviços gerais. Importante destacar que em nenhum momento perguntou-se diretamente qual o significado monetário da palavra renda (ou viver da renda, ou renda complementar), porque, no Brasil, esse assunto ainda é tabu, principalmente entre aqueles profissionais que realizam atividades informais do mercado de trabalho. A opção dos autores é sempre manter o distanciamento adequado e respeitoso ao tabu, para não causar constrangimentos aos entrevistados.

Durante as pesquisas de campo, consolidadas pela observação direta da vida comunitária e pela realização das entrevistas, que possibilitaram contato direto com os pescadores e os membros de suas famílias, foi possível observar que o ofício de pescador, historicamente passado de geração a geração, atualmente, desperta pouco interesse entre seus filhos, ou mesmo tem sido pouco estimulado para seus descendentes, fazendo com que optem e procurem exercer outras atividades também realizadas na praia, como, por exemplo, bombeiro e salva vidas. Interessante observar, também, que em algumas entrevistas foram observados os termos hobby e esporte, vinculados à atividade, como que a ressaltar que consideram a dificuldade de sobreviver apenas com a renda da pesca e esperam que seus filhos procurem outras atividades profissionais mais seguras e rentáveis.

Outro ponto evidenciado é que a pesca é citada por $71 \%$ dos entrevistados como atividade complementar (considerando apenas aqueles que desenvolvem uma segunda fonte de renda), frente a $28,5 \%$ atribuídos à maricultura, que começou a ser desenvolvida há duas décadas no local. Aliando-se os fatores expostos, como a baixa quantidade de trabalhadores associados ativos, pouco incentivo das novas geraçóes e percepção da pesca como renda complementar, pode-se sugerir uma desconstruçáo da pesca enquanto atividade econômica rentável, capaz de gerar sustento para as famílias que dela dependem. Interessante confrontar esse aspecto, que, aparentemente, pode sugerir exclusivamente uma desvantagem econômica da atividade, mas que, no dizer de Rocha et al. (2012), é apontado como uma vantagem social, pois é uma atividade que possibilita agregação de novas fontes de renda, uma vez que a pesca artesanal pode não garantir o sustento integral das famílias envolvidas nessa atividade.

Ao buscar as possíveis causas dessa desconstruçáo, verificou-se nas falas que não se trata de pouco valor econômico atribuído ao pescado, ausência de mercado consumidor, nem de vontade de exercer a atividade, mas, principalmente, a diminuição dos estoques pesqueiros. E, mais uma vez, Rocha et al. (2012) nos indicam que esse aspecto não é somente local, como pudemos observar na praia da Cocanha, mas é, também, global. De acordo com os autores, muitas comunidades ao redor do planeta encontramse na exclusiva dependência da pesca artesanal, embora a atividade venha, ao longo dos anos, sofrendo com a escassez de recursos pesqueiros, bem como com a exclusão do acesso ao exercício da atividade (Rocha et al. 2012: 536).

Essa tendência de redução, salientada pelos entrevistados, pode ser observada na análise da produção pesqueira e estuarina do Estado de São Paulo dos últimos 40 anos (Figura 3).

De acordo com o Programa de Monitoramento da Atividade Pesqueira - PMAP (São Paulo, 2011), os dados preliminares da produção da pesca marinha e estuarina do Estado de Sáo Paulo apontam um decréscimo significativo ano a ano, principalmente a partir do ano de 1985, apresentado o ano de 2010 como o de menor produçáo já registrada em vinte anos no Litoral Paulista.

Assim, diante da visível queda na produção pesqueira, a mitilicultura, que, inicialmente, foi colocada como um complemento ou uma atividade alternativa, já que seu início junto à comunidade é recente, passou a ser considerada central na comunidade estudada. Entretanto, é importante salientar que a questão da redução da produção também está presente nos discursos dos maricultores. Mesmo que as 


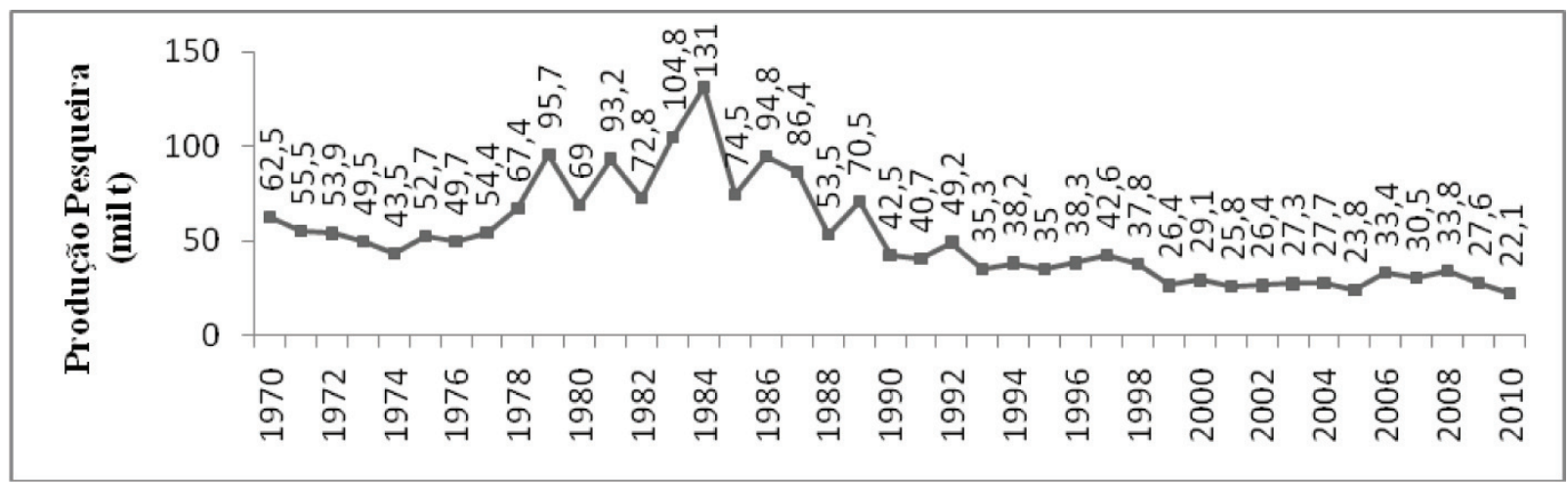

Figura 3. Produção pesqueira marítima e estuarina do Estado de São Paulo de 1970 a 2010, segundo o informe da produção pesqueira do Programa de monitoramento da atividade pesqueira da Secretaria da Agricultura do estado de São Paulo.

Figure 3. Estuarine and marine fish production of the State of São Paulo 1970 to 2010.

origens e associaçóes atribuídas a essa diminuição difiram nas opiniōes entre pescadores e maricultores, dada às peculiaridades de cada atividade, a queda de $\mathrm{kg}$ por caixa de pescado é substituída pelas perdas em $\mathrm{kg}$ por corda de mexilhão. A diminuição dos estoques pesqueiros e as perdas no cultivo de mexilhão podem ser identificadas como itens centrais nos discursos e principais fatores relacionados às modificações ocorridas na pesca.

Muitos pesquisadores têm considerado a percepção dos pescadores artesanais e o saber tradicional de comunidades pesqueiras, mesmo centrados em diferentes metodologias e abordagens teóricas (Moritz-Sohn et al., 2013; Santos et al., 2012; Stori et al., 2012; Delicado et al., 2012; Vasques \& Couto, 2011; Glaría, 2010; Burda \& Schavetti, 2008; Silvano et al., 2006; Mourão \& Nordi, 2006; Aswani \& Hamilton, 2004; Begossi et al., 2001; Begossi, 1996), como inesgotável fonte de saber e de referência, sob vários aspectos que contribuem para entender de forma mais ampla a realidade do uso de recursos naturais e do lugar de onde se fala. Sendo que, em muitas situaçóes, essa percepção e esses saberes podem influir em planejamento, adaptação e mitigação para inúmeras situaçôes de risco e vulnerabilidade sociais a que muitas dessas populaçôes estão submetidas.

Inserindo-nos nesse debate, compartilhamos com Delicado et al. (2012), que sustentam, em seu trabalho, que os pescadores artesanais e, consequentemente, os maricultores, já que essa última atividade passou a ser um desdobramento da atividade anteriormente ou concomitantemente realizada, por viverem e trabalharem junto ao mar, detêm conhecimento específico sobre a paisagem marítima e a costa, reconhecem diferenças de marés, ventos, correntes, fauna marinha e outros fenômenos cotidianamente observados, sobre os quais conseguem entender e mesmo fazer previsóes e associaçóes.

Assim, tendo como ponto de partida a queda da produçáo pesqueira que a análise das entrevistas realizadas evidenciou, podem-se identificar, nos discursos, três categorias implicativas: mudanças na pesca, no clima e na paisagem da praia, que consistiram naquelas que se apresentaram com maior frequência nos relatos e que, segundo os entrevistados, estão relacionadas às modificaçóes ocorridas nas últimas décadas na atividade laboral dos pescadores e maricultores da região estudada, e que estão sendo tratadas neste artigo como consequências de mudanças ambientais globais.

\subsection{Mudanças ambientais globais, recursos marinhos e a percepçáo dos entrevistados}

No Brasil, considerando especialmente as análises de Dias et al. (2009:4) sobre a localização da populaçáo mundial e sua proximidade dos litorais, já mencionada anteriormente, verifica-se que esta questão requer bastante atenção e um olhar cuidadoso por parte da sociedade e dos gestores públicos. No caso do Litoral Norte do estado de Sáo Paulo, essa proximidade tem promovido uma forte ação antrópica, que aliada às condiçóes geomorfológicas e, as fragilidades dos ecossistemas da regiáo, requerem atenção redobrada, tanto de pesquisadores quanto dos poderes instituídos.

Tendo como base a construçáo de um olhar interdisciplinar, que vem sendo consolidado, nos últimos dez anos, pelos autores, para analisar essa região, afirmase que as mudanças ambientais globais mais evidentes na região de estudo, apontado pelas pesquisas já realizadas e que já foram abordadas em outros momentos são ampliação de rodovias para acesso a regiáo, megaprojetos tecnológicos, principalmente voltados para o setor de gás e petróleo, migraçáo intensa, construção de empreendimentos imobiliários, principalmente condomínios voltados para lazer de segunda residência, construçôes de moradias populares para atender ao crescente número de trabalhadores que são atraídos para a construção civil e o trabalho nas empresas de extração de petróleo e gás, aumento da violência urbana, do comprometimento da saúde física e mental dos moradores e turismo de massa desordenado (Seixas et al., 2011; Seixas et al., 2012; Botterill et al. 2013; Seixas et al., in press). Aliado a esses aspectos ocorre, significativa mudança na paisagem das praias, aumento de intensidade e volume de chuvas (Arnell \& Gosling, 2013), e improbidade do uso da maioria das praias para lazer na maior parte do ano, no município de Caraguatatuba. Além de acidentes como o 
recente vazamento de petróleo ocorrido em abril de 2013, no Terminal Almirante Barroso (TEBAR) da Petrobras, na Praia de São Francisco em São Sebastião, que se espalhou e atingiu a praia da Cocanha, além de outras 14 praias de São Sebastião e Caraguatatuba ${ }^{3}$.

Os efeitos das mudanças ambientais globais para comunidades costeiras já tem sido bastante analisados por alguns autores, que tem dado destaque especial para as mudanças climáticas, como Adger (1999), Fuchs et al. (2011); Cinner et al. (2012); Nicolodi \& Petermann (2010); Delicado et al. (2012). Nossos estudos no Litoral Norte, como mencionado anteriormente, revelam que o clima é mais um dos fatores desse conjunto de impactos para regiōes costeiras e suas comunidades (Seixas et al, 2011; Seixas et $a l, 2012)$. O efeito negativo das mudanças do clima para a sobrevivência dessas comunidades está sendo objeto desse artigo, na medida em que a percepçáo desses trabalhadores sobre o produto do seu trabalho fez se evidenciar através de suas entrevistas. E é com a premissa de "os pescadores artesanais são testemunhas privilegiadas destas mudanças" (Delicado et al., 2012:438) que procuramos analisar a percepção dos pescadores artesanais da praia da Cocanha sobre os temas relacionados.

\subsubsection{Percepçáo sobre a variaçáo da temperatura da água do mar, do volume de chuvas e da imprevisibilidade das condiçóes climáticas}

No Brasil, considerando especialmente as análises de Dias et al. (2009:4) sobre a localização da população mundial e sua proximidade dos litorais, já mencionada anteriormente, verifica-se que esta questão requer bastante atenção e um olhar cuidadoso por parte da sociedade e dos gestores públicos. No caso do Litoral Norte do estado de São Paulo, essa proximidade tem promovido uma forte ação antrópica, que, aliada às condiçôes geomorfológicas e às fragilidades dos ecossistemas da região, requer atenção redobrada, tanto de pesquisadores quanto dos poderes instituídos.

Tendo como base a construção de um olhar interdisciplinar, que vem sendo consolidado, nos últimos dez anos, pelos autores, para analisar essa regiáo, afirmase que as mudanças ambientais globais mais evidentes na região de estudo, apontadas pelas pesquisas já realizadas e que já foram abordadas em outros momentos, são ampliação de rodovias para acesso à região, megaprojetos tecnológicos, principalmente voltados para o setor de gás e petróleo, migração intensa, construção de empreendimentos imobiliários, principalmente condomínios voltados para lazer de segunda residência, construçóes de moradias populares para atender ao crescente número de trabalhadores que são atraídos para a construçáo civil e o trabalho nas empresas de extração de petróleo e gás, aumento da violência urbana, do comprometimento da saúde física e mental dos moradores e turismo de massa desordenado (Seixas et al., 2011; Seixas et al., 2012; Botterill et al. 2013; Seixas et al., in press). Aliado a

3 - Folha de São Paulo, 9 de abril 2013, Cotidiano, Caderno 5: Petrobras é multada em R \$10 mi por vazamento no litoral paulista, de R. Hiar e N. Cancian. esses aspectos, ocorre significativa mudança na paisagem das praias, aumento de intensidade e volume de chuvas (Arnell \& Gosling, 2013) e improbidade do uso da maioria das praias para lazer (São Paulo, 2011), na maior parte do ano, no município de Caraguatatuba; além de acidentes como o recente vazamento de petróleo ocorrido em abril de 2013, no Terminal Almirante Barroso (TEBAR) da Petrobras, na Praia de São Francisco, em São Sebastião, que se espalhou e atingiu a praia da Cocanha, além de outras 14 praias de São Sebastião e Caraguatatuba (Hiar; Cancian, 2013).

Os efeitos das mudanças ambientais globais para comunidades costeiras já têm sido bastante analisados por alguns autores, que têm dado destaque especial para as mudanças climáticas, como Adger (1999), Fuchs et al. (2011); Cinner et al. (2012); Nicolodi e Petermann (2010); Delicado et al. (2012). Nossos estudos no Litoral Norte, como mencionado anteriormente, revelam que o clima é mais um dos fatores desse conjunto de impactos para regiōes costeiras e suas comunidades (Seixas et al, 2011; Seixas et $a l, 2012)$. O efeito negativo das mudanças do clima para a sobrevivência dessas comunidades está sendo objeto deste artigo, na medida em que a percepção desses trabalhadores sobre o produto do seu trabalho fez-se evidenciar através de suas entrevistas. E é com a premissa de "os pescadores artesanais são testemunhas privilegiadas destas mudanças" (Delicado et al., 2012:438) que procuramos analisar a percepção dos pescadores artesanais da praia da Cocanha sobre os temas relacionados.

\subsubsection{Percepção sobre a variação da temperatura da água do mar, do volume de chuvas e da imprevisibilidade das condiçóes climáticas}

Nas entrevistas com os pescadores, ficou evidente a percepção que possuem sobre a variação da temperatura da água do mar ao longo do tempo e a relaçáo dessa mudança com a diminuição da sua produção pesqueira. Importante ressaltar que Abraham et al. (2013), em importante artigo especialmente voltado para análises globais de temperaturas dos oceanos, apontam que, apesar da importância de medir com precisão a temperatura do oceano, ainda permanece como um problema desafiador para cientistas climáticos. Embora tenham ocorrido avanços significativos na quantidade e qualidade dos aferimentos, ainda se fazem necessárias medidas que abrangem amplas escalas espaciais e temporais para a determinação de variaçôes históricas de temperatura. Assim, mesmo sendo uma tarefa difícil, as consideraçóes a partir da memória e das mediçóes que realizam com os instrumentos que possuem são um dado importante e significativo.

A temperatura do mar ideal para a criação do mexilhão é abaixo de 24 graus, se a temperatura muda, prejudica na criação. A temperatura do mar está aumentando, antigamente a temperatura normal no inverno era $18^{\circ}$ a $19^{\circ} \mathrm{C}$, agora chega a $21^{\circ}$ e $22^{\circ} \mathrm{C}$. No verão a temperatura normal era de $24^{\circ} \mathrm{C}$, agora chega a $26^{\circ}$ e $27^{\circ} \mathrm{C}$. A temperatura alta (aproximadamente $27^{\circ} \mathrm{C}$ ) favorece a craca, que acaba dominando o mexilhão. No ano de 
2006/2007 o veräo foi muito intenso, chegamos a perder 60\% da produção do mexilhão, de 14 quilos, conseguimos tirar apenas 4 quilos de cada corda. (Entrevistado 3, 2009).

Aliado à menção da percepção do aumento da temperatura da água do mar, também mencionaram aumento do volume de chuvas e da imprevisibilidade das condiçóes climáticas, que são percebidas como de grande interferência nas suas atividades, tanto de pesca como na maricultura. Significativamente, o aumento da temperatura é citado por 97\% dos entrevistados, refletindo a acentuada interferência que essa questão representa na atividade pesqueira e na maricultura. Os depoimentos a seguir ajudam a elucidar esse aspecto:

Ano passado teve El niña de fevereiro até junho. Teve dia que chegou a 32 graus de manhã, imagina ao meio dia. $O$ ideal para o mexilhão $e ́$ de 22 a 26 graus e salinidade 34 a 36. A salinidade dá normalmente $34 / 35$, mas chegou a 36. (Entrevistado 10, 2011).

Água quente e clara dá lodo na rede. Dá ardentia [reflexo na água] e a rede brilha. Pra pesca é melhor no inverno, que a água fica turva. E também no calor se você solta a rede e o peixe cai logo, amanhä, a hora que for tirar o peixe já está podre, com essa água quente. Não sei qual foi a mudança mas está mais quente. (Entrevistado 11, 2011).

Estudos recentes voltados para mudanças globais no ambiente e especialmente para o impacto de variaçóes climáticas na pesca e na aquicultura apontam que os oceanos têm apresentado variaçóes climáticas, embora não de forma global, de mais ou menos $3^{\circ} \mathrm{C}$, e que esse efeito combinado altera, também, a salinidade dos mares, diminuindo a disponibilidade de nutrientes e, consequentemente, diminuindo os estoques na pesca de captura marinha e continental e interferindo na aquicultura (Barangue $\&$ Perry, 2012:9; Barrington et al., 2009).

Salienta-se que, entre os maricultores, o aumento da temperatura configura uma das modificaçóes ambientais mais impactantes sobre a mitilicultura, devido ao limite de temperatura ideal para o desenvolvimento dos mexilhóes, que varia entre 22 a 26 graus. Essa limitação se mostra determinante ao observarmos um maior volume de produção em regióes mais frias, como Santa Catarina. Com a temperatura mais elevada, existe o favorecimento e a proliferação de cracas (e que não possuem valor econômico agregado), que competem com os mexilhóes por alimento e substrato de fixação, acentuando ainda mais as perdas. Importante destacar que a questão dos impactos negativos das mudanças climáticas em relação às comunidades que são dependentes dos recursos marinhos já foi também apontada por outros autores, como Adger (1999); Furlan et al. (2011); Cinner et al. (2012). Os discursos abaixo evidenciam a percepçáo dos pescadores:

Quando a água não "tá" adequada d̀ temperatura, ele [o mexilhão] não fica a mesma coisa: nâo engorda, não fica bom. Quando "tá" magro, quem conhece sabe. Mas o cliente não nota. (Entrevistado 9, 2011).

Aliado à elevação da temperatura está o aumento da pluviosidade, que foi citada por $54 \%$ dos entrevistados. Os depoimentos a seguir ilustram esse aspecto:

Nos últimos três meses teve chuva direto, o mar ficou virado o ano todo, o pessoal perdeu uma tonelada de mexilhão, a temperatura da água aumentou, e o mexilhão depende de temperatura mais baixa para procriar. (Entrevistado 2, 2009).

Muda feio do nada, esse ano teve muita ressaca feia comparada com o ano passado, no caso do marisco acaba com a safra. (Entrevistado 1, 2009).

Agora a procura é bastante, muito mais que antes. Os antigos falam que antes tinha até para enterrar. Hoje tem muita perda, principalmente na ressaca (abril/maio). (Entrevistado 13, 2011).

Outra observação colocada pelos pescadores é a dificuldade em fazer previsóes sobre o tempo, fundamental para determinar a saída para o mar.

Hoje em dia não dá para saber se vai fazer sol amanhã ou se vai chover, é difícil organizar saidas para o mar. (Entrevistado 4, 2009).

No inverno melhora a pescaria, mas antes as estaçóes eram mais bem definidas. Agora no verão teve dias de frio de ter que sair de blusa de casa. (Entrevistado 8, 2011).

Ah, agora pra sair tem que conhecer o tempo. Com esse aquecimento, os ventos mudam as correntes. Se dá mudança no tempo, dá mudança no peixe, a corrente leva o peixe. Quando o mar amansa é que dá mais peixe. Com tempo ruim o pescador não pode sair. Despesa de barco grande pra ficar mais ou menos uma semana no mar vai de 15 a 20 mil reais, não dá pra ficar arriscando. (Entrevistado 7, 2011).

Importante considerar esses aspectos apontados nas entrevistas, porque acreditamos que muito desse saber contribuiria para mitigar problemas que já vêm sendo enfrentados e que poderão aumentar, na medida em que as regiôes costeiras estarâo cada vez mais sujeitas aos impactos de variações climáticas e pluviométricas nos próximos anos (Neves \& Muehe, 2008; Nicolodi \& Petermann, 2010). Nesse sentido, Vasques \& Couto (2011) apontam um aspecto bastante interessante sobre esse saber que é desconsiderado, em seu trabalho sobre a percepçáo dos pescadores e o período de defeso na pesca de arrasto, em Ilhéus, na Bahia (Brasil), dizendo que o defeso é a principal medida na pesca do camarão e que essa medida é elaborada por técnicos do Poder Público e por pesquisadores das universidades, não sendo levado em consideraçáo o conhecimento tradicional 
dos pescadores artesanais e o saber que detêm pela prática e tradição, o que, segundo os autores, poderia ser uma base de informaçôes importantes para o manejo dos recursos pesqueiros do local.

\subsubsection{Mudanças na paisagem, turismo e a percepçáo dos pescadores.}

Nos últimos anos, como já mencionado anteriormente e em outros momentos (Seixas et al., 2011; Seixas et al., 2012; Botterill et al., 2013), a regiâo da praia da Cocanha tem provocado um interesse expressivo do ponto de vista turístico, pois é uma região de exuberante beleza natural, o que, consequentemente, atrai muitos visitantes. Ao mesmo tempo, observou-se, durante as pesquisas de campo, que o aspecto turístico da praia está cada vez mais despertando o interesse da comunidade local, ao mesmo tempo em que promove, para alguns deles, um discurso em que também apontam aspectos negativos na atividade. Além do Festival do Mexilhão, que é apoiado pela Prefeitura do município, é possível realizar passeios turísticos em barcos e lanchas, conhecer a área de cultivo e as ilhas da região - Ilha e Ilhote da Cocanha. Essas atividades oferecem aos moradores, também, a possibilidade de aumento de sua renda.

$\mathrm{Na}$ Ilha da Cocanha, foi possível acompanhar o significativo crescimento de turistas para sua visitação. Em 2009, a ilha possuía como atrativo uma trilha que permite acesso ao seu topo, onde se encontra um casarão do início do século XX, e uma segunda prainha, além de um espaço, logo em sua entrada, com um restaurante improvisado para servir pratos típicos à base de mexilhóes. Em 2011, foi possível observar que o mesmo restaurante passou a contar com melhorias de infraestrutura e maior número de funcionários trabalhando, bem como uma média de 30 pessoas visitando o local nos finais de semana.

O turismo faz parte de uma dinâmica sem precedentes no mundo globalizado, mas, ao mesmo tempo em que pode incrementar e recuperar o trabalho humano em determinadas regióes do planeta, pode também promover impactos negativos do ponto de vista ambiental e cultural (Coriolano et al., 2008). No litoral brasileiro, esse fenômeno não é diferente, pois parte de pequenas comunidades que essencialmente viviam da pesca e de pequeno comércio passam a ter convivência com uma nova atividade e com novas demandas sociais e culturais, para as quais, na maior parte das vezes, não estão preparadas (Souza et al., 2008).

Assim, a tênue separação entre os aspectos positivos e negativos do turismo na praia da Cocanha também ficou explícita em várias das entrevistas realizadas. Por um lado, os entrevistados ressaltam que o produto do seu trabalho hoje possui um mercado consumidor maior, em função dos turistas que visitam a localidade, o que representa um aspecto positivo. Mas, por outro, reconhecem que negativamente sofrem os impactos diretos das atividades turísticas e do aumento de visitantes na região, pois não fizeram grandes reformas para receber um número maior de pessoas e não houve investimento nem planejamento do poder local para melhoria da infraestrutura regional, dos serviços públicos e do saneamento ambiental, o que acarreta, na maior parte do tempo, sobrecarga na infraestrutura local e na demanda de serviços públicos.
Verifica-se, assim, que a conjunção dos fatores analisados que envolvem impactos de dimensóes e origens variadas expressa uma situação de vulnerabilidade e risco que tem afetado de forma significativa a vida dessas comunidades estudadas.

\section{CONSIDERAÇÓES FINAIS}

A análise da percepçáo dos pescadores e maricultores da praia da Cocanha, em relaçáo às mudanças ambientais globais, expressas nos recursos marinhos em geral, apresentaram quatro categorias centrais de análise: transformaçôes na paisagem, variação da temperatura da água do mar, imprevisibilidade das condiçóes climáticas e a presença de um forte turismo na região onde vivem.

Dentre todas as categorias elencadas, suas percepçóes sobre as mudanças no clima, em especial o aumento da temperatura da água do mar, foram consideradas as mais expressivas, já que esta interfere diretamente sobre os recursos pesqueiros dos quais esta comunidade tem forte dependência, podendo ser considerado um fenômeno importante no conjunto de mudanças ambientais globais na região.

Outro aspecto importante salientado por eles durante as entrevistas diz respeito à mudança na diversidade de espécies encontradas, com a diminuiçấo de espécies nobres e que possuem um valor de mercado mais atrativo para venda. Segundo a opinião dos entrevistados, atribui-se grande parte dessas mudanças às atividades antropogênicas, que impactam o meio natural, sendo possível destacar o aumento do uso de embarcaçóes com motores e do óleo diesel, tanto na pesca quanto no turismo, e que interferem diretamente na qualidade do pescado; e da produçáo e falta de tratamento adequado de esgoto e seus reflexos na qualidade da água e, por consequência, no pescado e mexilhăo.

Ao mesmo tempo, observa-se que este grupo social encontra-se em uma situação de alta vulnerabilidade, e, apesar de os pescadores e maricultores perceberem, conforme salientado neste trabalho, os efeitos das mudanças climáticas nas suas atividades cotidianas, que atingem diretamente seu bem-estar, sua capacidade efetiva de gerenciar e mesmo minimizarseus efeitos, tanto individual quanto coletivamente, ainda é bastante reduzida e pouca considerada.

Nesse sentido, torna-se fundamental aprofundar essas questóes na medida em que esse grupo social poderá contribuir em muito, não só para identificação dos problemas, mas para mitigá-los, já que a relação que estabelecem com a natureza é muito intima e profunda, devendo ser priorizada.

\section{AGRADECIMENTOS}

Os autores agradecem à Fundação de Amparo à Pesquisa do Estado de São Paulo (FAPESP) pelo apoio recebido para a realização da pesquisa que origina este artigo, através dos processos $n^{\circ} 2010 / 20811-5, n^{\circ} 2008 / 58159-7$ e $n^{\circ}$ 2011/22370-9. A primeira autora é Bolsista de Produtividade do Conselho Nacional de Desenvolvimento Científico e Tecnológico - CNPq - Brasil. 


\section{REFERÊNCIAS BIBLIOGRÁFICAS:}

Abraham, J.P.; Baringer, M.; Bindoff, N.L; Boyer, T; Cheng, L.J.; Church, J.A.; Conroy, J.L.; Domingues, C.M.; Fasull, J.T.; Gilson, J.; Goni, G.; Good, S.A.; Gorman, J. M.; Gouretski, V.; Ishii, M.; Johnson, G.C.; Kizu, S.; Lyman, J.M.; Macdonald, A.M.; Minkowycz, W.J.; Moffitt, S.E.; Palmer, M.D.; Piola, A.R.; Reseghetti, F.; Schuckmann, K.; Trenberth, K.E.; Velicogna, I. (2013) - A review of global ocean temperature observations: Implications for ocean heat content estimates and climate change, Reviews of Geophysics, 51(3):450-483. DOI: 10.1002/rog.20022

Adger, W.N. (1999) - Social Vulnerability to Climate Change and Extremes in Coastal Vietnam. World Development, 27(2):249-269. DOI: 10.1016/S0305750X(98)00136-3

Adger, W.N.; Kelly, P.M. (2005) - Social vulnerability and resilience. In: W. Neil Adger, P. Mick Kelly \& Nguyen Huu Ninh (eds.), Living with environmental change: Social vulnerability, adaptation and resilience in Vietnam, pp.1934, Routledge, London, U.K. ISBN:978-0415217224

Arnell, N.W.; Gosling, S.N. (2013) - The impacts of climate change on river flow regimes at the global scale. Journal of Hydrology, 486:351-364. DOI: 10.1016/j. jhydrol.2013.02.010

Aswani, S.; Hamilton, R. (2004) - Integrating indigenous ecological knowledge and customary sea tenure with marine and social science for conservation of bumphead parrotfish (Bolpometodon muricatum) in the Roviana Lagoon, Solomon Islands. Environmental Conservation, 31:1-15.

Barange, M.; Perry, R.I. (2012) - Repercusiones físicas y ecológicas del cambio climático en la pesca de captura marina y continental y em la acuicultura. In: Kevern Cochrane; Cassandra De Young; Doris Soto \& Tarûb Bahri (eds.). Consecuencias del cambio climático para la pesca y la acuicultura. Visión de conjunto del estado actual de los conocimientos cientifficicos. Documento Técnico de Pesca y Aquicultura, 530, pp. 7-118, FAO, Roma, Italia. ISBN 978-9253063475

Barrington, K.; Chopin, T.; Robinson, S. (2009) - Integrated multi-trophic aquaculture (IMTA) in marine temperate waters. In: Doris Soto (org.). Integrated mariculture: a global review. FAO Fisheries and Aquaculture Technical Paper, 529, pp. 7-46, FAO, Rome, Italy. ISBN 978-925-106387-3

Begossi, A.; Hanazaki, N.; Peroni, N. (2000) - Knowledge and use of biodiversity in Brazilian hot spots. Environment, Development and Sustainability, 2(3-4):177-193. DOI: 10.1023/A:1011409923520

Bindoff, N.L.; Willebrand, J. (coord.) (2007) - Observations: Oceanic Climate Change and Sea Level. In: Climate Change 2007: Working Group I: The Physical Science Basis, pp.386-432. Disponível em http://www.ipcc.ch/ publications_and_data/ar $4 / \mathrm{wg} 1 / \mathrm{en} / \mathrm{ch} 5 . \mathrm{html}$

Bitencourt, N.L.R.; Rocha, I.O. (in press) - Percepção das Populaçóes Costeiras sobre os Efeitos dos Eventos Adversos no Extremo Sul de Santa Catarina - Brasil, Revista da Gestão Costeira Integrada, in press. DOI: $10.5894 /$ rgci 408
Boscardin, N.R. (2008) - A produção aquícola brasileira. In: Antonio Ostrensky, José Roberto Borghetti \& Doris Soto (eds.), Aquicultura no Brasil: o desafio é crescer, pp.159- 182, SEAP - Secretaria Especial de Aquicultura e Pescas / FAO - Organização das Nações Unidas para Agricultura e Alimentação, Brasília, DF, Brasil, ISBN: 978-8560930005. Disponível on-line em http://gia.org. $\mathrm{br} /$ site/images/livros/livros/2008\%20Aquicultura.pdf

Botterill, T.D.; Seixas, S.R.C.; Hoeffel, J.L. (2013) - Tourism and Transgression: Resort Development, Crime and the Drug Economy. Tourism Planning \& Development, p. 1-15. DOI: $10.1080 / 21568316.2013 .815269$

Burda, C.L.; Schavetti, A. (2008) - Análise ecológica da pesca artesanal em quatro comunidades pesqueiras da Costa de Itacaré, Bahia, Brasil: Subsídios para a Gestão Territorial. Revista da Gestão Costeira Integrada, 8(2):149168. DOI: $10.5894 /$ rgci136

Cinner, J.E.; McClanahan, T.R.; Graham, N.A.J.; Daw, T.M.; Maina, J.; Stead, S.M.; Wamukota, A.; Brown, K.; Bodin, O. (2012) - Vulnerability of coastal communities to key impacts of climate change on coral reef fisheries. GlobalEnvironmental Change, 22:12-20.DOI: 10.1016/j. gloenvcha.2011.09.018

Confalonieri, U.E.C. (2005) - Mudanças climáticas e saúde humana. In: M.K. Poppe \& E.L. La Rovere (org.), Mudança do Clima, pp.66-171, Cadernos NAE, Brasília, DF, Brasil.

Cooper, C.; Fletcher, J.; Wanhill, S.; Gilbert, D.; Shepherd, R. (2002) - Turismo, princípios eprática. 784p., Bookman, Porto Alegre, Brasil. ISBN: 9788577800148

Coriolano, L.N.M.T. (2008) - Litoral do Ceará: espaço de poder, conflito e lazer. Revista da Gestão Costeira Integrada, 8(2):277-287. DOI: $10.5894 / \mathrm{rgci} 131$

Coriolano, L.N.M.T.; Leitão, C.S.; Vasconcelos, F.P. (2008) - Sustentabilidades e Insustentabilidades do Turismo Litorâneo. Revista da Gestão Costeira Integrada, 8(2):1123. DOI: $10.5894 /$ rgci130

Delicado, A.; Schmidt, L.; Guerreiro, S.; Gomes, C. (2012) - Pescadores, conhecimento local e mudanças costeiras no litoral Português. Revista de Gestão Costeira Integrada, 12(4):437-451. DOI: $10.5894 / \mathrm{rgci} 349$

Dias, J.A.; Carmo, J.A. do; Polette, M. (2009) - As zonas costeiras no contexto dos Recursos Marinhos - Prefácio. Revista da Gestão Costeira Integrada 9(1):3-5. DOI: $10.5894 /$ rgci 168

Egler, C.A.G.; Gusmão, P.P. (in press) - Gestão costeira e adaptação às mudanças climáticas: o caso da Regiáo Metropolitana do Rio de Janeiro, Brasil. Revista da Gestão Costeira Integrada, in press. DOI: 10.5894/rgci370

Fagundes, L.; Gelli, V.C.; Otani, M.; Vicente, M.C.M.; Fredo, C.F. (2004) - Perfil socioeconômico dos mitilicultores do litoral paulista. Informaçôes Econômicas, 34(5):47-59.

Fuchs, R.; Conran, M.; Louis, E. (2011) - Climate change and Asia's coastal urban cities. Can they meet the challenge? Environment and Urbanization Asia, 2(1):1328. DOI: $10.1177 / 097542531000200103$

Furlan, A.; Bonotto, D.M.; Gumiere, S.J. (2011) Development of environmental and natural vulnerability maps for Brazilian coastal at São Sebastião in São Paulo State. Environmental Earth Sciences, 64(3):13-28. DOI: 10.1007/s12665-010-0886-7 
Giddens, A. (2010) - A Politica da Mudança Climática. 316 p. Zahar, Rio de Janeiro, Brasil. ISBN: 9788537802618

Glaría, V. (2010) - Sujetos colectivos en búsqueda de sustentabilidad pesquera: relatos de los miembros de uma comunidad de pescadores artesanales, $\mathrm{V}$ región, Chile. Polis, Revista de la Universidad Bolivariana, 9(27):109127. DOI: $10.4067 /$ S0718-65682010000300006

Honey, M. (2010) - Ecoturism and sustainable development: who owns paradise? 568p., Island Press, Washington, USA. ISBN-10: 1597261262

Josupeit, H. (2005) - Mussel production and markets. Fao/Globefish, Rome, Italy. Disponível on-line em http://www.globefish.org/index.php?id=2508

Kotir, J.H. (2010) - Climate change and variability in SubSaharan Africa: a review of current and future trends and impacts on agriculture and food security. Environmental Development and Sustainability, 13:587-605. DOI: 10.1007/s10668-010-9278-0

Krippendorf, J. (2000) - Sociologia do turismo: para uma nova compreensáo do lazer e das viagens. $3^{\mathrm{a}}$ ed., 272p., Aleph, Sáo Paulo, SP, Brasil. ISBN:9788576570851

Machado, R.C.A.; Gusmão, L.G.; Câmara, L.; Vila-Nova, D.A.; Leal, A.F.G.; Oliveira, A.C.A.; Soares, C.L.R.S. (2009) - Percepção socioambiental dos turistas e trabalhadores da praia de Porto de Galinhas (PernambucoBrasil) acerca do ecossistema recifal. Revista da Gestão Costeira Integrada, 9(3):71-78. DOI: 10.5894/rgci158

Manzoni, G. (2004) - Mitilicultura: a produção de sementes em laboratório pode ser uma solução viável. Revista Panorama da Aqüicultura, 14(83):31-33.

Marengo, J.A. (2006) - Mudanças climáticas globais e seus efeitos sobre a biodiversidade: caracterização do clima atual e definição das alteraçôes climáticas para o território brasileiro ao longo do século XXI. 212p., Ministério do Meio Ambiente, Secretaria de Biodiversidade e Florestas Brasília, DF, Brasil. ISBN: 85-7738-038-6. Disponível on-line em http://www.mma.gov.br/estruturas/imprensa/_arquivos/ livro\%20completo.pdf

Marengo, J.A.; Valverde, M.C. (2007) - Caracterização do clima no século XX e cenário de mudanças de clima para o Brasil no século XXI usando os modelos do IPCC-AR4. Revista Multiciência, 8:5-28.

Marques, H.L.A.; Bordon, I.C.A.C.; Alves, J.L.; Medeiros, A.M.Z. (2008) - Produção de mexilhôes jovens (sementes) por maricultores da Praia da Cocanha, Caraguatatuba (SP). Revista Tecnologia \& Inovação Agropecuária, 1(2):8793.

Mendonça, F. (2005) - Clima, tropicalidade e saúde: uma perspectiva a partir da intensificação do aquecimento global. Revista Brasileira de Climatologia, 1(1):100-112.

Mendonça, R. (2006) - Turismo ou meio ambiente: uma falsa oposição? In: Lemos, A. (org.). 305 p. Turismo: impactos sócio-ambientais. Hucitec, São Paulo, SP, Brasil, p. 14-36. ISBN 8527103435

Miller, R.B.; Jacobson, H.K. (1992) - Research on the human components of global change. Next steps. Global Environmental Change, 12:170- 182. DOI: 10.1016/0959-3780(92)90001-N

Min, S.K; Zhang, X.; Zwiers, F.W.; Hegerl, G. (2011)-Human contribution to more-intense precipitation extremes. Nature, 470:378-381. DOI:10.1038/nature09763
Moretz-Sohn, C.D.; Carvalho, T.P.; Silva, F.J.N. Filho; Gastão, F.G.C.; Garcez, D.S.; Soares, M.O. (2013) - Pescadores artesanais e a implementação de áreas marinhas protegidas: Estudo de caso no nordeste do Brasil. Revista da Gestão Costeira Integrada, 13(2):193204. DOI: $10.5894 /$ rgci382

Mourão, J. da S.; Nordi, N. (2006) - Pescadores, peixes, espaço e tempo: Uma abordagem etnoecológica. INCI, Caracas, 31(5). Disponível em http://www.scielo. org.ve/scielo.php?script=sci_arttext\&pid=S037818442006000500007 \&lng=es\&nrm=iso.

Neves, C.F; Muehe, D. (2008) - Vulnerabilidade, impactos e adaptação a mudanças do clima: a zona costeira. In: Brasil. Ministério da Ciência e Tecnologia/Centro de Gestão e Estudos Estratégicos. Parcerias Estratégicas. Edição Especial Mudança do clima no Brasil: vulnerabilidade, impactos e adaptação, Brasília, DF, Brasil, 27 (dezembro):217-296.

Nicolodi, J.L.; Petermann, R.M. (2010) - Mudanças Climáticas e a Vulnerabilidade da Zona Costeira do Brasil: Aspectos ambientais, sociais e tecnológicos. Revista da Gestão Costeira Integrada 10(2):151-177. DOI: $10.5894 /$ rgci206

O’Brien, K.L.; Leichenko R.M. (2002) - Double exposure: assessing the impacts of climate change within the context of economic globalization. Global Environmental Change, 10:221 -232. DOI: 10.1016/S0959-3780(00)00021-2

Ostrensky, A.; Boeger, W.A. (2008) - Principais problemas enfrentados atualmente pela aqüicultura brasileira. In: Antonio Ostrensky, José Roberto Borghetti \& Doris Soto (eds.), Aquicultura no Brasil: o desafio é crescer, pp.135-158, SEAP - Secretaria Especial de Aquicultura e Pescas / FAO - Organização das Naçóes Unidas para Agricultura e Alimentação, Brasília, DF, Brasil, ISBN: 978-8560930005. Disponível on-line em http://gia.org. br/site/images/livros/livros/2008\%20Aquicultura.pdf.

Ostrensky, A.; Boeger, W.A.; Chammas, M.A. (2008) Potencial para o desenvolvimento da aquicultura no Brasil. In: Antonio Ostrensky, José Roberto Borghetti \& Doris Soto (eds.), Aquicultura no Brasil: o desafio é crescer, pp.159- 182, SEAP - Secretaria Especial de Aquicultura e Pescas / FAO - Organização das Nações Unidas para Agricultura e Alimentação, Brasília, DF, Brasil, ISBN: 978-8560930005. Disponível on-line em http://gia.org. br/site/images/livros/livros/2008\%20Aquicultura.pdf

Oven, K.J.; Curtis, S.E.; Reanet, S.; Riva, M.; Stewart, M.G.; Ohlemüller, R.; Dunn, C.E.; Nodwell, S.; Dominelli, L.; Holden, R. (2012) - Climate change and health and social care: defining future hazard, vulnerability and risk for infrastructure systems supporting older people's health care in England. Applied Geography, 33:16-24. DOI: 10.1016/j.apgeog.2011.05.012

Patz, A. J.; Gibbs, H.K.; Foley, J.A.; Rogers, J.V.; Smith, K.R. (2007) - Climate change and global health: quantifying a growing ethical crisis. EcoHealth, 4(4):397-405. DOI: 10.1007/s10393-007-0141-1

Pestana, D.; Pie, M.R.; Pilchowski, R.W. (2008) - Organização e Administração do setor para o desenvolvimento da aquicultura. In: Antonio Ostrensky, José Roberto Borghetti \& Doris Soto (eds.), Aquicultura no Brasil: o desafio é crescer, pp.115-134, SEAP - Secretaria Especial de Aquicultura e Pescas / FAO - Organização das Nações Unidas para Agricultura e Alimentação, Brasília, 
DF, Brasil, ISBN: 978-8560930005. Disponível on-line em http://gia.org.br/site/images/livros/livros/2008\%20 Aquicultura.pdf.

Prado, L.R.T. (2001) - Pescadores de Caraguatatuba: histórias $e$ estórias. 82p., Fundação Educacional e Cultural de Caraguatatuba/FUNDACC, Caraguatatuba, São Paulo, Brasil.

Rocha, P.H.G.O.; Carvalho, D.A.P.; Pinheiro, L.S. (2008) - A Costa de Paracuru: Turismo, Ocupação e Perfil do Usuário. Revista da Gestão Costeira Integrada, 8(2):247258. DOI: $10.5894 /$ rgci129

Ruschmann, D.M. (2006) - Turismo e planejamento sustentável: A proteção do meio ambiente. 199 p., Papirus, Campinas, Brasil. ISBN 8530804392

Santos, A.J.F.R; Azeiteiro, U.M.; Sousa, F.; Alves, F. (2012) - A importância dos conhecimentos e dos modos de vida locais no desenvolvimento sustentável: estudo exploratório sobre o impacto da Reserva Natural das Ilhas Berlengas (Portugal) na comunidade piscatória. Revista da Gestão Costeira Integrada, 12(4):429-436. DOI: $10.5894 / \mathrm{rgci} 321$

Seixas, S.R.C.; Hoeffel, J.L.M.; Botterill, T.D.; Vianna, P.V.C.; Renk, M. (in press) - Social and Environmental Changes on the North Coast of the State of Sao Paulo: Opening new lines of research on violence, tourism, crime and the subjective. In: A. Henzel, (org.) Tourism and Violence. Ashgate Publishing Ltd., Farnham, UK.

Seixas, S.R.C.; Hoeffel, J.L.M.; Renk, M.; Vieira, S.A.; Mello, L.F.; Vianna, P.V.C. (2011) - Mudanças Ambientais Globais, Vulnerabilidade e Risco: Impactos na Subjetividade em Caraguatatuba, Litoral Norte Paulista. Revista VITAS - Visóes Transdisciplinares sobre Ambiente e Sociedade, Niterói, RJ, Brasil 1(2): setembro de 2011. Disponível em http://www.uff.br/revistavitas.

Seixas, S.R.C.; Renk, M.; Hoeffel, J.L.M; Conceição, A.L.; Asmus, G.F. (2012) - Global Environmental Changes and Impacts on Fishing Activities in the Northern Coast of São Paulo, Brazil. In: William Holt (ed.), Urban Areas and Global Climate Change, pp.301-319. DOI: 10.1108/ S1047-0042(2012)0000012015

Sherbinin, A.; Schiller, A.; Pulsipher, A. (2007) - The vulnerability of global cities to climate hazards. Environment and Urbanization, 19(1):39-64. DOI: $10.1177 / 0956247807076725$

Silvano, R.A.M.; MacCord, P.F.L.; Lima, R.V.; Begossi, A. (2006) - When Does this Fish Spawn? Fishermen's Local Knowledge of Migration and Reproduction of Brazilian Coastal Fishes. Environmental Biology of Fish, 76(24):371-386.
Silvestri, F. (2009) - Determinacão da producão de resíduos sólidos provenientes do cultivo de mexilhóes na região da Ilha da Cocanha-Caraguatatuba, SP. Dissertação de Mestrado em Oceanografia Biológica, Instituto de Biociências, Universidade de São Paulo, SP, Brasil. Não publicado.

Silvestri, F.; Bernadochi, L.C.; Turra, A. (2011) - Os maricultores e o poder público: um estudo de caso no litoral norte de São Paulo. Boletim do Instituto de Pesca, São Paulo, 37(1):103 - 114.

Sinau (2009) - Sistema de Informações das Autorizaçóes de Uso de águas de Dominio da União para fins de Aquicultura. Disponível em http://tuna.seap.gov.br/seap/html/ aquicultura/index.html

Solomon, S.; Qin, D.; Manning, M.; Chen, Z.; Marquis, M.; Averyt, K.B.; Tignor, M.; Miller, H.L. (eds.) (2007) - Contribution of working group to the fourth assessment report of the intergovernmental panel on climate change. 996p., Cambridge University Press, Cambridge, UK. ISBN 978-0-521-70596-7

Sousa, P.H.G.O.; Carvalho, D.A.P.; Pinheiro, L.S. (2008) - A Costa de Paracuru: Turismo, Ocupação e Perfil do Usuário. Revista da Gestão Costeira Integrada, 8(2):247258. DOI: $10.5894 /$ rgci129

Souza, S.C. (2009) - Elites Políticas em Caraguatatuba. In: Anais Seminário Nacional Sociologia \& Politica, 1, pp.101, Universidade Federal do Paraná, Curitiba, Paraná Brasil.

Stori, F.T.; Nordi, N.; Abessa, D.M.S. (2012) - Mecanismos socioecológicos e práticas tradicionais de pesca na comunidade caiçara da Ilha Diana (Santos, Brasil) e suas transformações. Revista da Gestão Costeira Integrada, 12(4):521-533. DOI: $10.5894 /$ rgci355

Turner II, B.L.; Kasperson, R.E; Meyer, W.B.; Dow, K.M.; Golding, D.; Kaperson, J.X.; Mitchell, R.C.; Ratick, S.J. (1990) - Two types of global environmental change Definitional and spatial-scale issues in their human dimensions. Global Environmental Change, 1:14-22.

Vasques, R.O.R.; Couto, E.C.G. (2011) - Percepção dos Pescadores quanto ao estabelecimento do Período de Defeso da Pesca de Arrasto para a Região de Ilhéus (Bahia, Brasil). Revista da Gestão Costeira Integrada, 11(4):479485. DOI: $10.5894 /$ rgci291 